\title{
Stigma - Diskriminierung - Bewältigung
}

Wolfgang Gaebel, Hans-Jürgen Möller, Wulf Rössler (Hrsg.):

Stigma - Diskriminierung - Bewältigung. Der Umgang mit sozialer Ausgrenzung

psychisch Kranker, 295 Seiten, 1. Auflage, Einband, ISBN 3-17-017819-9, Kohl-

hammer Verlag, Stuttgart

$\mathrm{D}$ as vorliegende Buch bietet eine ausführliche Darstellung der aktuellen Themen Stigmatisierung und Diskriminierung psychisch Kranker in unserer Gesellschaft. Wichtiger noch, es beinhaltet zudem den entscheidenden Aspekt der Bewältigung dieser Punkte.

Das Buch gliedert sich in der Präsentation von Grundlagen und empirischer Evidenz, Praxiserfahrungen und Praxisbeispielen dieser drei Themen. Weiterhin wird der sachlichen Darstellung von AntistigmaInitiativen wie zum Beispiel „Open the doors“ ausreichend Platz eingeräumt.

Die langjährige Erfahrung der Autoren mit den genannten Themen in ihrer klinischen und gesellschaftlichen Ausprägung und wissenschaftlichen Bearbeitung zieht sich in fundierter Weise durch das gesamte Buch. Zur Veranschaulichung tragen dabei in sehr guter Weise durchweg gelungene $\mathrm{Ab}$ bildungen und Tabellen bei. Auch die Fallbeispiele helfen den bisher noch nicht so sehr mit diesen Themen vertrauten Kollegen, sich an dieses Gebiet heranzutasten. Der Umfang der einzelnen Kapitel ist ausgewogen und inhaltlich fließend ineinander übergehend.

Das vorliegende Buch ist ein Vielautorenwerk, dennoch bleiben die einzelnen Kapitel in fundiertem Wissen und präziser Darstellung gleichbleibend gut. Sehr wertvoll ist der Anhang mit der Aufführung von Organisationen und Verbänden, dieser ermöglicht den schnellen und konkreten Zugriff zu AntistigmaInitiativen.
Das Sachregister könnte ein wenig ausführlicher gestaltet sein, dennoch ist hiermit eine schnelle Orientierung auch in der vorliegenden Weise möglich.

Das vorliegende Buch schließt in vorbildlicher Form eine im Bereich der Psychiatrie bisher bestehende Lücke. Es sollte dazu beitragen, gleichermaßen das Interesse von Fachkollegen, Betroffenen und Angehörigen für die Bereiche Stigma, Diskriminierung und deren Bewältigung in der Psychiatrie zu wecken.

Die Versachlichung dieser Themen ist nun erstmals in einem Buch durchgehend behandelt, damit ist ein Schritt zur weiteren Integration und weniger emotional geführten Diskussion dieser Bereiche getan. Die Autoren mögen einen Anstoß gegeben haben, diese Thematik in Zukunft auch in die bewährten Standardwerke der Psychiatrie einzufügen.

Priv.-Doz. Dr. med. E. Davids, Essen

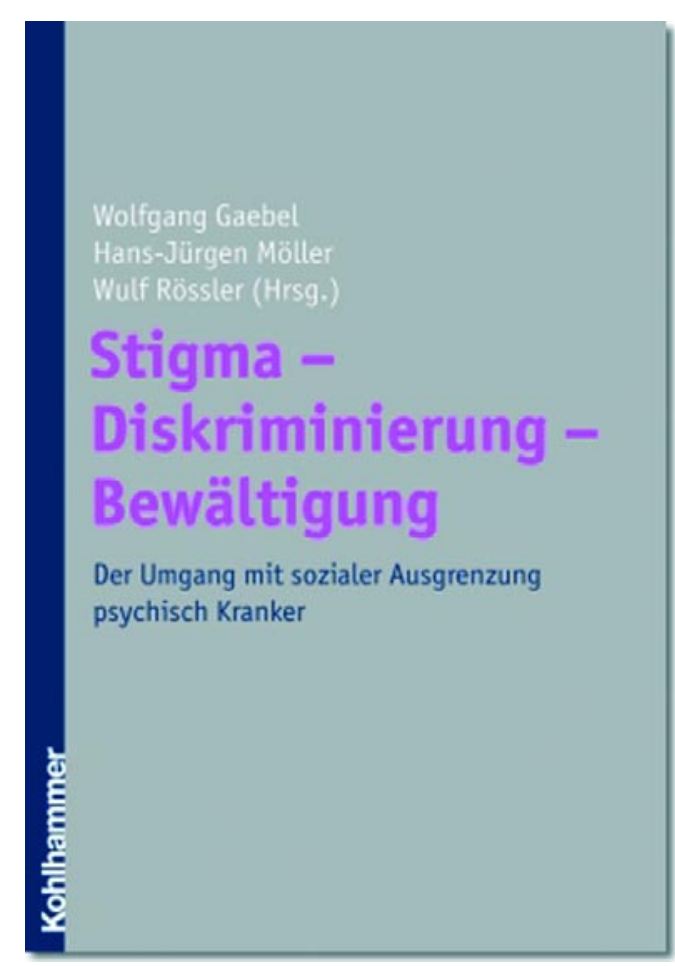

